\title{
O PODER DA INFÂNCIA: espiritualidade e política em afroperspectiva
}

Renato Noguera ${ }^{1}$

Resumo: Nós assumimos uma abordagem afroperspectivista para analisar o "poder da infância". Este artigo tem objetivo de apresentar a infância como um modo de ser extraordinário. Após a leitura de duas narrativas espirituais, nós vinculamos a infância com poder verdadeiro. Em termos afroperspectivistas, a política e a espiritualidade só são atividades mais bem sucedidas a partir da infância. A análise comparativa entre Cristianismo e Candomblé levou-nos ao ponto de vista de que ambas convergem num aspecto central. A infância é o fundamento da conexão entre as dimensões espiritual e material, e a superação desta dualidade. A Infância é chave para produção de uma política biocêntrica.

Palavras-Chave: Infância; Espiritualidade; Política.

\section{THE CHILDHOOD’S POWER: spirituality and politics in afroperspective}

\begin{abstract}
We take an afroperspectivist approach to analyze the "Childhood's Power". This article aims to present the childhood like extraordinary way of life. Following the reading of two spiritual narratives, we bond the childhood with true power. Made in afroperspectivists terms, the Politics and Spirituality are only activities more be successful by childhood. The comparative analyze between Christianity and Candomblé, led us to the partial conclusion that both converge in a central aspect. The childhood is foundation of the connection between spiritual and material dimensions and overcoming this duality. The childhood is key to the production of a biocentric policy.
\end{abstract}

Keywords: Childhood; Spirituality; Politics.

\section{Primeiras palavras: cosmosentidos afro-pindorâmicos}

Numa galáxia distante existiam mundos diferentes, diversas moradas. Todos os seres viviam sob a força da Infância. Fossem bichos humanos, flores, vegetais, bichos onças ou de outros tipos; todos os seres nasciam, cresciam e morriam assumindo o mistério da vida, experimentando conflitos e disputas, choros e sorrisos. Todos se divertiam diversamente sem conversão e sem pensar igual. Das disputas não surgiam gente derrotada. Mas, somente pessoas que aprendiam a brincar de muitos modos. Não existia paraíso, tampouco inferno. O governo era feito de brincadeiras, todas as pessoas podiam cirandar em todas as posições da roda. Brincar era tanto ordem quanto mandamento, brincar era a regra e brincar era a maneira de exercer a desobediência, o brincar era a norma vivente da Infância. Viver era sinônimo de infância e brincadeira.

Numa manhã chuvosa e fria na maior parte do planeta, um meteoro fez estragos e trouxe uma irradiação perigosa que fazia as pessoas perderem a força da Infância. Ora, a força da Infância permitia brincar, fazia com que gente humana pudesse conversar com outros bichos e plantas. A força da Infância impedia a existência de

\footnotetext{
${ }^{1}$ Doutor em Filosofia pela UFRJ. Professor Associado da UFRRJ, lotado no Departamento de Educação e Sociedade (DES), docente permanente do Programa de Pós-Graduação em Educação, Contextos Contemporâneos e Demandas Populares (PPGEduc).
} 
prisões e manicômios, os crimes inexistiam. A brincadeira era sagrada e inalienável.

Mas, o meteoro trouxe a radiação da adultez e, num prazo que ninguém sabe ao certo: o adultescimento tomou todo o planeta. Desde então, fizeram acordos sociais criando um Estado. As religiões se multiplicaram e no início duas mais equipadas de armas começaram a brigar por fiéis. Na política os partidos passaram a brigar. As disputas agora não podiam terminar empatadas, a derrota humilhante produzia um grupo que se sentia orgulhosamente vitorioso. Desde então, o remédio miraculoso para os desafios da vida tem sido a recuperação e manutenção da Infância, uma força humana esquecida e desacreditada pelo brutal adultescimento e colonização da vida.

Essa sucinta fábula expõe resumidamente o que pretendemos dizer com o título “O poder da Infância: espiritualidade e política em afroperspectiva”. Primeiro porque nosso pensamento é baseado na maneira afroperspectivista de interpelar as questões, um modo intelectual de abordar os problemas, investindo em matrizes africanas e indígenas de pensamento. Outra coisa que merece alguma atenção é o uso do "nós" ao invés do "eu". Alguma leitora, algum leitor poderia perguntar: "por que escrever na primeira pessoa do plural?". Eu mantenho o desejo de escrever na primeira pessoa do plural - ou melhor, nós mantemos - porque estou acompanhado de ideias e pensamentos que me foram presenteados por autoras e autores diversos, minhas avós, meus avôs, minha mãe, meu pai, minha companheira de jornada conjugal e nossas minhas filhas ${ }^{2}$, inclua-se todas as crianças que carinhosamente me ensinam, assim como estudantes de graduação, mestrado e doutorado e demais colegas de pesquisas que trabalham comigo. Dito isso, vamos ao ponto. O que denominamos aqui de "poder da Infância" é um projeto sem esperança e sem medo. Um clássico debate afroperspectivista a respeito dos temas que unem autoras e autores neste dossiê precisamente intitulado Descolonizar as crianças em processos de (des)aprendizagens com os saberes religiosos: o que pode uma criança nos ensinar?

A afroperspectividade é uma maneira de estudar, ler, investigar, pesquisar, filosofar, compor ensaios e sustentar alternativas diante de temas e problemas que a vida nos impõe. Devido ao escopo deste ensaio não caberá uma longa apresentação do pensamento afroperspectivista; mas, uma sucinta descrição dos seus elementos centrais. A afroperspectividade remete a cosmo-sentidos africanos e pindorâmicos para pensar-

\footnotetext{
${ }^{2}$ Minhas duas filhas eram crianças com nove e três anos de idade na ocasião que finalizei este texto e me ensinavam cotidianamente o humor poderoso das crianças frente aos desafios de existir.
} 
sentir o mundo. Por cosmo-sentidos deve-se entender a recusa à tese clássica da cosmovisão, tal como nos apresenta a sociologia nigeriana da etnia iorubá, Oyèrónkẹ Oyěwùmí. A cosmovisão - aqui entendida como visão de mundo - não deixa de ser, conforme Oyěwùmí, uma limitação ocidental.

O termo 'visão de mundo' que se usa no Ocidente para sintetizar a lógica cultural de uma sociedade, expressa adequadamente a prerrogativa ocidental da dimensão visual. Mas, teríamos um resultado eurocêntrico se utilizássemos essa expressão para nos referirmos a culturas que provavelmente dão prioridade para outros sentidos [...] usaremos 'sentido de mundo' em referência à sociedade ioruba e outras culturas que podem privilegiar outros sentidos ou uma combinação deles (OYĚWÙMÍ, 2017, p. 39).

A afroperspectividade opera articulando as possibilidades advindas de todos os sentidos para apresentar o mundo. De modo que não se trata de uma visão de mundo; mas, lançamos mão de olfatos de mundo, audição de mundo, tato de mundo, paladar de mundo. Daí, numa sinestésica articulação de sentidos de mundo, encontramos caminhos para nossa hipótese: espiritualidades e políticas que reestabeleçam laços com a Infância. É importante registrar que África aqui remete às concepções de Cheik Anta Diop (1967), Marimba Ani (1994) e Molefi Asante (1987). África remete aos sentidos de mundo que têm em seu eixo duas características: xenofilia e matrifocalidade. Para Diop (1967), todos os povos africanos têm esses pontos em comum, recepção do estrangeiro como alguém que traz conhecimento e protagonismo da família materna. Pindorama, tal como nos ensina o instigante pensador quilombola Antônio Bispo dos Santos (2015), é um tipo de conceito guarda-chuva que abriga os sentidos de mundo dos povos indígenas. Afinal, conforme Bispo dos Santos (2015, p. 27), o Brasil se chamava Pindorama, nome dado pelos povos de línguas do tronco tupi que habitavam a região antes das invasões europeias. Não é simples estabelecer um ponto comum entre 305 povos indígenas que habitam o território brasileiro sem fazer uma generalização, à primeira vista, reducionista. Mas, as culturas indígenas (pindorâmicas), tal como quilombolas, são biointeracionistas (SANTOS, 2015, p. 81). O que significa que o trabalho não é colocado como uma atividade mais importante do que viver. Uma maneira de identificar isso está na própria construção da infância moderna. Nas culturas em que o trabalho assume centralidade na vida, as crianças eram questionadas (ou ainda são?) sobre o que gostariam de ser quando se tornassem adultas. Em culturas biointeracionistas, as crianças vivem em função do presente, não de uma utopia futurista na qual elas passarão a ser "gente" apenas quando forem adultas. Sem dúvida, 
as contribuições de vários trabalhos do campo dos estudos sociais da infância Hardman, 2001; Corsaro, 1997; James, Jenks e Prout, 1998; Delalande, 2006; Sarmento, 2004 - contribuíram decisivamente para problematizar essa visão sobre as crianças.

A afroperspectividade é uma abordagem que articula leituras diversas. De modo que nos debruçamos nos estudos e assumindo que os lugares de fala são compostos por: pertencimentos étnico-raciais, gêneros, orientações sexuais e perspectivas políticas, debruçado sobre a antropóloga guarani nhandeva Sandra Benites; o cientista social e ativista negro Abdias do Nascimento; o xamã e filósofo yanomami Davi Kopenawa; o pan-africanista e sistematizador da afrocentricidade Molefi Asante; a antropóloga branca Tânia Stolze Lima e o filósofo quilombola Antônio Bispo dos Santos. Nossos trabalhos de campo têm sido com crianças em aldeias, escolas, praças públicas, quilombos, nas rodas de capoeira, nas rodas de jongo e em terreiros de religiões de matriz africana. Em todos esses territórios, as vozes que nos interessam são as das crianças. Pela razão que a antropóloga branca britânica Christina Toren (1988a, 1988b) afirma que os estudos etnográficos com crianças reiteram hipóteses de que elas possuem autonomia e revelam coisas que os adultos não expressam. Clarice Cohn, antropóloga branca brasileira, no livro Antropologia da criança, contribui com a ideia de que uma escuta atenta das crianças viabiliza a descoberta de coisas desconhecidas por adultos. O que as antropólogas Christina Torene e Clarice Cohn indicam é que as crianças revelam aspectos inusitados das culturas. Essas considerações são muito importantes para uma pesquisa afroperspectivista. Outros elementos decisivos são as infâncias de alguns povos africanos e indígenas que vivem em território brasileiro. Destacamos dois exemplos: os Maxacali que vivem em Minas Gerais (ALVAREZ, 2004) e os Wolof (NOGUERA, 2017). Num caso, a "criança é o fio que tece as várias dimensões da sociabilidade Maxakali. É através dela que se inaugura a relação com o outro" (ALVAREZ, 2004, p. 53). No contexto Wolof, encontramos um provérbio que diz: "se você pensa que é muito pequeno para fazer a diferença, é porque nunca passou a noite com um mosquito". Nos dois casos as referências são feitas às crianças. Elas são encaradas como altamente capazes de transformar a sociedade. Aqui interpretamos ligeiramente, porque não temos espaço para longas digressões, não se trata apenas das crianças. Mas, de uma outra categoria: infância. Uma condição através da qual as crianças se expressam com mais frequência do que os adultos. Em resumo, a combinação das produções intelectuais negras e indígenas - a afropespectividade - tem 
uma ênfase na definição filosófica da infância como cosmosentidos que permitem reinaugurar experiências e produzir mais-valia de vida. Ora, por mais-valia de vida entendemos aquilo que o filósofo branco estadunidense-canadense Brian Massumi (2017) sustenta baseado em leituras de filósofos brancos europeus instigantes como Gilles Deleuze e Henri Bergson. Pois bem, o que é mais-valia de vida?

O que está em excesso na situação, sua sobrecarga de intensidade, é canalizado pelo valor de brincadeira do jogo. É um valor de excesso, no excesso: uma mais-valia. É mais-valia de animação, de vivacidade uma mais-valia de vida, irredutivelmente qualitativa, nivelada de forma ativa como viver.

A mais-valia de vida, que é uma das -esquidades dos gestos vitais da brincadeira, corresponde ao que Raymond Ruyer chama de $\mathrm{O}$ rendimento estético de atividade. $\mathrm{O}$ rendimento estético é o excesso qualitativo de um ato vivido puramente por si só, como um valor em si, acima e contra qualquer função que também possa ocupar (MASSUMI, 2017, p. 25).

A mais-valia é o aumento da intensidade da vida, uma celebração de existir. $\mathrm{O}$ filósofo branco argentino Walter Kohan nos brinda de modo fenomenal com uma das definições mais precisas de Infância. Kohan diz: "a Infância é o nome de um milagre, o da interrupção do ser das coisas pela entrada de seu outro, do outro do ser, a condição de toda e qualquer diferença" (KOHAN, 2010, p.134).

Numa leitura original de pensadores brancos europeus como François Lyotard, o filósofo argentino nos apresenta uma perspectiva que combina bastante com nossos cosmosentidos afroperspectivistas: a Infância é a emergência de um acontecimento que interrompe o fluxo corriqueiro das coisas, suscitando algo, ao mesmo tempo, ímpar e banal. Ímpar porque cada momento é único e extraordinário, e, banal porque tudo que acontece é ordinário e comum. Infância nos convida a reinventar o mundo.

Cabe destacar nossa hipótese de inspiração kohaniana: a Infância seria justamente a fase, a condição, os cosmo-sentidos que melhor apresentariam aqueles fenômenos que, inexplicavelmente, chamamos de milagre. De onde, hipoteticamente sugerimos que a Infância seja justamente a melhor maneira de traduzir milagre. Ora, se concordamos com a ideia de que "somos habitados pela infância para muito além de uma fase cronológica da vida" (KOHAN, 2015, p. 222), é a partir dessas considerações que costuramos a nossa hipótese central. Para pensarmos algo acerca da espiritualidade e da política que produza mais-valia de vida, podendo encantar novamente um mundo em crise, será preciso reestabelecer radicalmente a infância de todos os seres, inclusive das pessoas adultas. 


\section{As narrativas no campo da espiritualidade}

Em afroperspectiva, a espiritualidade é diferente da religiosidade. A primeira nasceu com a própria humanidade, enquanto a segunda emerge em contextos históricosociais e culturais específicos. A espiritualidade remete ao mistério da existência em suas dimensões inexplicáveis: por que existimos? De onde viemos e para onde vamos? Qual o sentido da vida? A religiosidade encampa as mesmas questões e ergue instituições com ritos, doutrinas e liturgias próprias.

Como se daria uma espiritualidade que produza mais-valia de vida? A resposta é simples: reestabelecendo a Infância como condição humana capaz de reunir experiências espirituais restauradoras e ações políticas transformadoras e democráticas. A nossa aposta é de que somente através da Infância podemos realizar uma vida espiritual individual e coletiva satisfatória. E, ao mesmo tempo, apenas o protagonismo da Infância pode enfrentar de modo qualificado as crises políticas mais severas. Nós vamos compartilhar duas histórias: Taiwo e Kehinde, e, Quem é maior no reino dos céus?, a partir delas, construiremos nossos argumentos em favor de uma espiritualidade inter-religiosa e de uma agenda política, nos dois casos ancoradas na Infância como princípio orientador e visão de mundo. Sem dúvida, uma questão importante a ser respondida será: “o que entendemos por Infância?”. Assunto que voltaremos adiante.

Vamos iniciar por uma narrativa iorubana que fala de uma cidade em que a Morte, cujo nome é Icu, chegou querendo levar todo mundo que estava vivo. O conjunto de versos é mais ou menos como segue adiante.

Num reino ioruba, a rainha Oxum e o rei Xangô tiveram filhos gêmeos (ibejis) idênticos chamados Taiwo e Kehinde. Por razões que aqui não cabem ligadas à disputa do trono, os dois meninos foram viver com Iemanjá no reino de Orunmilá, guardião de Ifá. Iemanjá era a mãe adotiva dos ibjeis e tinha muito amor pelas duas crianças. Icu, a Morte, foi visitar a aldeia de Orunmilá e não quis mais ir embora. De modo que bodes morriam, pessoas velhas, jovens e crianças morriam, pássaros morriam, flores morriam, plantações de inhame morriam, árvores morriam, galinhas morriam. Orunmilá pediu que Icu saísse do povoado. Icu, a Morte, disse que só sairia de alguém fosse capaz de obrigá-la a fazer algo que ela não quisesse. Com alguma pressa, Orunmilá recomendou que algumas embaixadoras e alguns embaixadores reunissem-se com Icu. Lá se foi uma comitiva munida de uma retórica capaz de convencer uma zebra a visitar uma leoa faminta. Mas, a comitiva não voltou. Então, Orunmilá enviou pequeno exército de 
guerreiras e guerreiros capazes de usar a espada como uma pantera negra usa suas garras. Mas, o pequeno exército não voltou. Depois que muita gente, tanto de paz e de guerra, foram levadas pela Morte, nenhuma pessoa do reino aceitava o convite de Orunmilá para pedir que Icu parasse de levar as pessoas. Sem a intervenção de alguém, a cada dia mais bichos morriam, cabritas, cabritos, vacas e bois deitavam para não levantar. Então, Orunmilá consultou Ifá (o sistema divinatório). O segredo revelado indicou que duas crianças: justamente os gêmeos Taiwo e Kehinde, os gêmeos (ibejis), deveriam ir conversar com o Icu, a Morte. Os meninos viviam para brincar e adoravam tocar um tambor dado por sua mãe Iemanjá. É preciso dizer que as duas crianças eram as mais levadas do reino.

No dia seguinte ao convite de Orunmilá, Iemanjá relutou e não queria deixar que os filhos fossem encontrar a Morte. As crianças abraçaram a mãe e partiram animadas bolando um plano, elas queriam brincar com Icu. Elas foram conversar com a Morte da maneira que falavam com gente adulta: brincando, dançando e saltitando. Mas, com um detalhe importante. Taiwo e Kehinde sempre gostavam de pregar uma peça em quem não sabia que eles eram dois. Taiwo começou a tocar o tambor dançando, Icu gostou do que ouviu e se pôs a dançar ao lado da criança. Ao lado da estrada, atrás de arbustos estava Kehinde acompanhado a dupla por frestas entre folhas. Taiwo dançou, tocou, pulou, brincou e tudo isso na companhia da Morte. Um tempo depois, cansado Taiwo passou o tambor para Kehinde. Este tomou o lugar do irmão de modo discreto sem que a Morte percebesse. Ora, como Kehinde estava descansado, dançou, tocou, pulou e brincou com toda energia que tinha. Taiwo foi beber água, descansar e ficou atrás de arbustos observando a festa de seu irmão com a Morte. Taiwo cochilou e chegou a sonhar. Kehinde dançou, tocou, pulou e brincou por um tempo em que as pernas já não se aguentavam. Então, Taiwo despertou e vendo que o passo do irmão diminuía, espiou pelo arbusto e com cuidado saiu para tomar o lugar do irmão. Isso se repetiu por sete vezes, de modo que Icu já não aguentava mais. Daí, foi até a presença do rei Orunmilá e disse que tinha dançado mesmo sem querer e que por isso deixaria o reino. No dia seguinte, a celebração foi uma apoteose de tambores, sons de corda e de sopro. Taiwo e Kehinde, juntamente com todas as crianças, puseram gente adulta para dançar, incluindo Iemanjá e Orunmilá. Afinal, depois que duas crianças já tinham colocado a Morte para dançar, ninguém mais poderia resistir.

Essa história pode ser resumida num enunciado que voltaremos adiante. A Infância é mais poderosa do que a morte. Nós voltaremos a essa afirmação depois de 
acharmos o enunciado da próxima história. Na Bíblia, nos livros de Mateus, Marcos e Lucas encontramos passagens comuns. Aqui nos interessa especialmente uma em que a questão central é: “quem é o maior no reino dos céus?”. Vejamos, no livro de Mateus 18: 1,6 :

\begin{abstract}
Naquele momento os discípulos aproximaram-se de Jesus e perguntaram: 'Quem é o maior no Reino dos céus?'. E Jesus, chamando uma criança, colocou-a no meio deles. E disse: 'Com toda a certeza vos afirmo que, se não vos converterdes e não vos tornardes como crianças, de modo algum entrareis no Reino dos céus. Portanto, todo aquele que se tornar humilde, como esta criança, esse é o maior no Reino dos céus. $\mathrm{E}$ quem recebe uma destas crianças, em meu nome, a mim me recebe. Jesus adverte sobre as ciladas. Entretanto, se alguém fizer tropeçar um destes pequeninos que creem em mim, melhor lhe seria amarrar uma pedra de moinho no pescoço e se afogar nas profundezas do mar'.
\end{abstract}

Nós encontramos outras passagens sobre a mesma situação em Marcos.

Apresentaram-lhe então crianças para que as tocasse; mas os discípulos repreendiam os que as apresentavam. Vendo-o, Jesus indignou-se e disse-lhes: 'Deixai vir a mim os pequeninos e não os impeçais, porque o Reino de Deus é daqueles que se lhes assemelham. Em verdade vos digo: todo o que não receber o Reino de Deus com a mentalidade de uma criança, nele não entrará'. Em seguida, ele as abraçou e as abençoou, impondo-lhes as mãos (MARCOS 10: 13-16).

No livro de Lucas encontramos um trecho baseado no mesmo evento.

Trouxeram-lhe também criancinhas, para que ele as tocasse. Vendo isto, os discípulos as repreendiam. Jesus, porém, chamou-as e disse: 'Deixai vir a mim as criancinhas e não as impeçais, porque o Reino de Deus é daqueles que se parecem com elas. Em verdade vos declaro: quem não receber o Reino de Deus como uma criancinha, nele não entrará' (LUCAS 18: 15-17).

Essas passagens bíblicas podem ser interpretadas de que maneira? Aqui acompanhamos aquilo que o teólogo Alessandro Rocha toma como sua tarefa no estudo sistemático da Bíblia. "Nosso desafio consiste na proposição de uma abordagem metodológica que ofereça condições para uma ruptura com o discurso teológico sistemático unívoco" (ROCHA, 2007, p. 121). No mesmo livro, Rocha nos diz que: "não se deveria mais falar de discurso teológico, mas de discursos teológicos. Tanto a dimensão do discurso quanto a da teologia são pluralizadas" (ROCHA, 2007, p. 135). Dito isso, optamos por uma interpretação que pode ser resumida no enunciado: somente 
o estado de Infância propicia a entrada no reino dos céus.

De um lado, versos iorubas que estão presentes em religiões como Candomblé, culto a Ifá e Umbanda, dentre outras. De outro, os versos cristãos que estão presentes em religiões como o catolicismo apostólico romano, no vasto conjunto de denominações do protestantismo (evangélico) e no espiritismo kardecista, dentre outras. Em nossa interpretação afroperspectivista, o que todas possuem em comum é muito simples: a realização da espiritualidade só chega ao seu apogeu quando somos capazes de assumir a Infância como um estado existencial especial que nunca devemos perder. Nunca perder de vista o milagre cotidiano de existir, a mais-valia da vida que precisamos insistir em buscar. No campo da espiritualidade, o poder da Infância é o caminho para fazer a morte dançar e para entrar no reino dos céus.

$\mathrm{O}$ que significa dizer que as crianças colocam a morte para dançar? O que quer dizer que somente as crianças entram no reino dos céus? Numa abordagem afroperscpectivista, a Infância é o conceito espiritual que está presente nas duas narrativas religiosas. Aqui "criança" é uma metáfora para "Infância". De modo que interpretamos que no contexto do Candomblé, afirmarmos que a Infância é capaz de olhar diretamente para a morte e tomá-la como razão necessária para fazer da vida uma atividade brincante. O Cristianismo está dizendo que a Infância é o modo de vida que faz o seu habitat ser um paraíso porque o torna um território brincante. A Infância opera pelos desígnios da transformação, da produção de realidades porque reconfigura através de sua potência criadora. Um olhar infantil é capaz de se espantar diante do que é corriqueiro e enxergar coisas inusitadas nas situações mais regulares e ordinárias.

\section{As narrativas no campo da política}

No campo dos estudos políticos encontramos um vasto repertório de escolas e autorias relevantes. A afroperspectividade não tem fixação por autores e autoras, as leituras dos estudos são ditadas muito mais pela qualidade e tipos de problemas a serem enfrentados. Aqui partiremos inicialmente das investigações de dois autores. De um lado, o filósofo político branco estadunidense Michael Hardt e, de outro, o celebrado autor de Crítica da razão negra, o historiador e filósofo camaronês Achille Mbembe. Hardt fala do racismo imperial. O capitalismo e o racismo produziram uma combinação complexa que impôs uma modalidade de sociedade de controle em que a corrupção é o modo operacional por excelência. "A sociedade de controle (imperial ou pós-moderna) 
se caracteriza pela corrupção" (HARDT, p. 371). Mbembe debate o devir-negro do mundo, isto é, como o capitalismo contemporâneo, resultado de um processo de exploração brutal da mão-de-obra negra escravizada, toma emprestado esse modelo racista para organizar a produção. Mbembe explica que as pessoas negras escravizadas se transformaram em corpo-moeda, corpo-mercadoria e corpo-ferramenta. Nós estamos diante de uma racionalidade que articula racismo e mercado. Essa dupla face (racismo e mercado) é o elemento chave da racionalidade de toda política contemporânea neoliberal. Nós estamos falando da razão mercantilista.

A razão mercantilista considera, acima de tudo, o mundo como um ilimitado mercado, um espaço de livre concorrência e circulação. A ideia do mundo como superfície percorrida por relações comerciais que atravessam as fronteiras dos estados e ameaçam tornar obsoleta a sua soberania [...]. A ideia moderna de democracia, tal como o próprio liberalismo, é inseparável do projeto de globalização comercial, do qual a plantação e a colônia são o epicentro. Ora, sabemos que tanto a plantação como a colônia foram originalmente dispositivos raciais num cálculo geral sustentado pela relação de troca baseada na propriedade e no lucro (MBEMBE, 2014, p. 142).

Numa articulação entre Hardt e Mbembe, a política operaria sempre com dispositivos raciais. Ou seja, liberalismo e democracia contemporâneos foram erguidos com braços escravizados negros, à custa da exaustão de mulheres, homens e crianças negras. Nos contextos continentais fora da Europa, a população euro-descendente tem dominado as instituições políticas. Em comum, tanto Hardt e Mbembe, ainda que não formulem exatamente do mesmo modo, convergem num diagnóstico que enxerga o racismo como categoria analítica indispensável para falarmos de política. A questão central da maneira como o sistema político mundial se estabeleceu está naquilo que o branco britânico nascido na Índia, Rudyard Kippling, popularizou num poema de 1899 como "fardo do homem branco". Nesse contexto racista, a missão do homem branco seria civilizar o resto do mundo e o papel da Europa seria expandir, navegar mundo afora e levar "ordem e progresso" para realidades de selvagens infantis sem conhecimento. Nessa aventura civilizatória branca, agregaram uma instituição religiosa com os dogmas do Deus cristão eurocêntrico para converter pagãos dos outros cantos mundo. A hipótese afroperspectivista pode ser formulada da seguinte maneira, todas as mazelas de uma crise generalizada numa sociedade global têm um ponto de partida que se confunde com a linha de chegada. Ou seja, os brancos europeus inventaram que o "resto" do mundo estava doente e que tinham a cura. De onde segue o postulado de que 
a exploração advém de uma visão de mundo de que as civilizações brancas euro-cristãs são "adultas" o suficiente para ensinar as infantis.

O racismo foi, e continua sendo, justificativa ideológica para associar domínio colonialista de não-brancos como uma missão civilizadora branca que traz progressos científico e econômico. Europa tinha como missão ensinar a vida para os que não sabiam viver como humanos civilizados. A tese do britânico branco Charles Darwin em Origem das espécies foi tomada como uma das razões suficientes e necessárias para justificar que, na luta das espécies, os grupos mais adaptados poderiam naturalmente conquistar e dominar outros em benefício da sobrevivência da espécie. Termos como “evolução", "avanço" e "progresso" frequentaram, e ainda estão presentes, discursos políticos. Um tipo de utopia futurista que conclama as pessoas a buscar um futuro melhor. Um futuro que pode ser conquistado sob a liderança de representantes da razão. Em termos filosóficos afroperspectivistas, nossa hipótese é de que o racismo estrutural, assim como a corrupção, a obsessão por progresso e desenvolvimento são os elementos que põem a vida em risco. Os diversos modos de exploração decorrem de um fenômeno aqui designado de adultescimento. Ora, num trabalho de campo numa escola da região metropolitana do Rio de Janeiro coletamos e aprendemos a palavra "adultescer" com uma criança (NOGUERA; GUTMAN; FEITOSA, 2017). No contexto de uma pesquisa, uma menina negra de oito anos de idade falou que o problema do mundo era adultescer. Daí, depois das devidas autorizações, incorporamos o conceito, conjecturamos e debatemos os sentidos do verbo adultescer e do termo adultidade. Ora, adultidade é a chave para entender o que devemos evitar politicamente, um modo de vida que abandona o mistério da vida como algo inescapável. Numa análise panorâmica, adultescer é justamente um percurso de adulteração da biointeratividade que faz da vida uma experiência sem rótulos, radical e marcada pelo mistério de existir. Em termos afroperspectivistas, adultescer significa perder as forças brincantes de investir no mistério inexplicável de existir - milagre. Adultescer é abrir mão da mais-valia da vida. Adultescer é a forma por excelência de corrupção da vida, algo contra o qual não temos um remédio salvador. Mas, apenas, o reestabelecimento da infância pode nos convocar a superar o adultescimento. O que isso significa? Devido ao adultescimento, fazer política tem sido uma atividade de colonização da vida. Para descolonizá-la é preciso uma política brincante. Uma política brincante está apoiada no mais-valia da vida e no milagre, isto é, ela advém da Infância.

O psiquiatra branco estadunidense Stuart Brown é um dos principais 
articuladores e fundador do National Institute for Play (Nifplay), uma instituição de pesquisas sobre brincadeiras e jogos. Brown nos ajuda a pensar essa politica também. Pessoas adultas precisam brincar como atividade constante capaz de impulsionar maisvalia de vida.

\begin{abstract}
Brown nos faz voltar ao livro de 1938 de Johan Huizinga, porque coloca a brincadeira/jogo como elemento central da condição humana. Para Huizinga, podemos questionar e duvidar da existência de um ser divino, da justiça, da beleza; mas, não podemos negar a realidade da(o) brincadeira/jogo, instância que ultrapassa o mundo humano. Outra fonte relevante para o campo está nos estudos do neozelandês Brian SuttomSmith (1924-2015) que publicou a Ambiguidade da brincadeira, afirmando que a brincadeira não se opõe ao trabalho; mas, a depressão. Para Suttom-Smith, a brincadeira é uma atividade indispensável para o bem-estar humano (NOGUERA, 2017, p. 33).
\end{abstract}

Vale a pena repetir que foram as palavras de uma criança de oito anos chamada Olivia Griot, "adultescer é o que estraga o mundo", que nossa hipótese ganhou mais força. Foi num final de manhã de novembro de 2017, numa pesquisa de campo realizada numa escola da região metropolitana do Rio de Janeiro que essa menina nos ensinou o conceito de adultidade e seus derivados. A adultidade é entendida como a rival da Infância que habita tudo que vive. Nós estamos de acordo com ela e que, tal como sugere Huizinga somos seres lúdicos, a ludicidade - o jogo e a brincadeira - é que nos define como humanos; nunca o controle e a capacidade de destruição. Para Brown, o que compartilhamos com outras espécies animais é o "instinto brincante". Por isso, para pensarmos uma política que escape das armadilhas das utopias futuristas mêssianicas é preciso viver em estado de Infância. As políticas contemporâneas são artimanhas de disputas, sempre gestadas em perspectivas de corrupção, do racismo estrutural, do sexismo opressor, da heteronormatividade, do adultocentrismo e outras formas de dominação e opressão. Com isso, vale ressaltar que afrimar que frequentar a Infância não é uma panacéia que acaba com os conflitos. A Infância nos ajuda a conviver com os conflitos, com a generosidade de quem assume que o mistério da vida não precisa ser resolvido por meio de controle, mas, tão somente aceito como somente uma dádiva.

Em termos políticos, o poder da Infância se organiza por uma trama complexa. O Estado nunca deve representar a sociedade; os mais diversos setores precisam estar presentes formulando ativamente as formas de vida. A brincadeira deve ser uma obrigação ética e política. As pessoas adultas devem ser "obrigadas" a brincar e o 
trabalho não pode mais se organizar pelo falso binômio: subsistência ou acumulação de excedente. Bispo dos Santos (2015) nos ensina que a cultura quilombola informa que o melhor lugar para guardar peixes é no próprio rio e só se deve buscá-los quando for necessário alimentar-se. Isso não é uma lógica de subsistência; mas, de provisão.

No mundo da representação política é inconcebível que só adultos possam fazer política. O que confirmaria a afirmação do cineasta branco francês Jean-Luc Godard de que as crianças são prisioneiras políticas das pessoas adultas. Numa sociedade decente, óbvio que as crianças devem ter suas opiniões consideradas na produção da vida pública, inclusive com assentos nos poderes. Numa sociedade multirracial e pluriétnica, todos os grupos devem estar representados num tipo de ciranda de produção de práticas políticas. Por exemplo, no Brasil por muito tempo a maioria esmagadora dos parlamentares do congresso nacional era de homens brancos maiores de 50 anos. Ora, numa sociedade onde as mulheres são maioria e o povo negro (pessoas pretas e pardas) é mais da metade da população, não é razoável que o congresso seja exclusivamente branco, masculino e adulto. É inacreditável que no Brasil não tenhamos bancadas indígenas, bancadas quilombolas, bancadas dos povos de terreiro e outras tantas que pudessem trazer uma profunda e radical mudança de repertório por conta de sentidos de mundo realmente diversos. É preciso reinventar as maneiras de fazer política; mas, não se trata de apenas mudar os partidos que comandam a agenda de uma nação, porque geralmente possuem os mesmos cosmo-sentidos. Não é suficiente somente enxergar com o olhar de uma criança, mas, também ouvir, tatear, saborear e perceber os cheiros do mundo com a mesma curiosidade que as crianças possuem diante do que é ordinário e familiar.

O poder da Infância sugere politicamente a construção de uma sociedade que se assemelhe aos moldes das organizações indígenas e quilombolas em que o tempo livre intensifica a mais-valia de vida. No contexto urbano contemporâneo brasileiro isso é possível? Um dos primeiros passos seria fazer gente adulta brincar, decretando a obrigatoriedade de que tempo livre e preguiça não se submetam ao tempo do trabalho. É preciso implementar efetivamente a mais-valia da vida.

\section{Breve conclusão parcial ou misturando espiritualidade e política}

Nós estamos declarando guerra às utopias messiânicas que prometem um futuro melhor; declarando guerra aos projetos que nos impedem de enfrentar o presente; 
declarando guerra à ideia de que o futuro será melhor; declarando guerra à renovação sistemática de que o presente é sempre pior do que o passado e o futuro. Essa guerra não é porque não acreditamos que o futuro possa ser melhor, mas porque partimos de um ponto de vista, ou melhor, de pontos de sentidos que sugerem o óbvio, “o amanhã é hoje". Porque as crianças não são apenas o nosso futuro; mas, o nosso presente e, em certa medida, o nosso passado - todo adulto já foi criança.

Poder da Infância nos instiga a fazer uma coisa que pode soar estranha. Tal como nos diz o poeta branco paraense e amazônico Vicente Cecim, será preciso que as crianças ensinem pessoas adultas. Cecim disse algo muito relevante numa roda de conversa no II Congresso Métodos Fronteiriços. Um evento realizado de 28 a 31 de agosto de 2017, na Universidade Federal de Rondônia (UNIR). Cecim falou que a melhor saída da crise que nos assola está nas crianças deixarem de aprender com pessoas adultas e começarem a inventar suas formas de organizar o mundo. A maisvalia de vida é o poder da Infância. Talvez, seja a grande mensagem espiritual tanto do cristianismo quanto do Candomblé: precisamos ser crianças, ou melhor, investir na Infância que vive e persiste em todos os seres vivos. Porque mais-valia de vida, a redenção, a vitória diante da morte, a comunhão com Deus e a incorporação do axé divino que permite o equilíbrio profundo só podem ser vivenciados em estado de Infância. Por outro lado, o maior de todos os projetos políticos, o mais audacioso é aquele que se sustenta justamente pela capacidade infantil de brincar e fazer do jogo uma aventura em que não seja preciso vencer ou perder; mas, seja apenas necessário biointeragir em favor de uma democracia baseada na "cultura do empate", isto é, numa competição colaborativa na qual o jogo e a brincadeira não se orientem pela busca da vitória, mas pela procura do equilíbrio. O que precisamos para uma espiritualidade autêntica, independente de filiações religiosas? O que fazer para uma vida política em que seja possível atendermos às demandas mais díspares e ideologias em choque? Infância. O primeiro passo: investir naquilo que promove a mais-valia de vida. É preciso que escutemos as crianças - pessoas na faixa etária de zero a 12 anos incompletos de acordo com códigos jurídicos nacionais - e a Infância que habita a cada um de nós: essa potência criativa que as crianças geralmente vivenciam mais do que os adultos. Porém, esta Infância está sempre acessível a cada um de nós, principalmente quando assumirmos que o milagre (outro nome para mais-valia de vida?) está contido nos mistérios diários que esquecemos de nomear. 


\section{Referências}

ANI, Marimba. Yuguru: an African-centered critique of European cultural thought and behavior. Trenton: African World, 1994.

ASANTE, Molefi Kete. Afrocentricity: the theory of social change. 3rd. ed. Trenton: Africa World, 1988.

ASANTE, Molefi Kete. The afrocentric idea. Philadelphia: Temple University, 1987.

ASANTE, Molefi Kete. Afrocentricidade: notas sobre uma posição disciplinar. In: NASCIMENTO, Elisa Larkin. Afrocentricidade: uma abordagem epistemológica inovadora. Tradução de Carlos Alberto Medeiros. São Paulo: Selo Negro, 2009. p. 93 110.

CORSARO, William. The sociology of childhood. Thousand Oaks: Pine Forge, 1997.

DIAKITÉ, Baba Wagué. O dom da infância: memórias de um garoto africano.

Tradução Marcos Bagno. São Paulo: Edições SM, 2012.

DIOP, Cheikh Anta. Antériorité des civilisations nègres: mythe ou vérité historique?. Paris: Présence Africaine, 1967.

DIOP, Cheikh Anta. Nations nègres et culture. Paris: Présence africaine, 1954.

DIOP, Cheikh Anta. Parenté génétique de l'égyptien pharaonique et des langues négro-africaines, Paris: IFAN/NEA, 1977.

COHN, Clarice. Antropologia da criança. Rio de Janeiro: Zahar, 2005a.

COHN, Clarice. O desenho das crianças e o antropólogo: reflexões a partir das crianças mebengokré- xikrin. Comunicação apresentada na $6^{\text {a }}$ Reunión de antropología del Mercosur, Montevidéo, Uruguai, 2005 b.

DELALANDE, Julie. Le concept heuristique de culture infantile. In: SIROTA, R. (dir.). Éléments pour une sociologie de l'énfance. Rennes: Presses Universitaires de Rennes, p. 1.572-1.590, 2006.

HARDMAN, Charlotte. Can be there an anthropology of children? Childhood, vol. 8, n. 4 , Londres/Nova Deli: Thousand Oaks/Sag, p. 501-517., 2001.

JAMES, Allison; JENKS, Chris; PROUT, Alan. Theorizing Childhood. Cambridge: Polity, 1998.

LIMA, Tânia Stolze. Um peixe olhou para mim. o povo Yudjá e a perspectiva, Rio de Janeiro/São Paulo, NuTI/ISA/Unesp, 2005.

LIMA, Tânia Stolze.Uma história do dois, do uno e do terceiro. In: QUEIROZ, Ruben Caixeta de; NOBRE, Renarde Freire (Orgs.). Lévi-Strauss: leituras brasileiras. Belo Horizonte: Editora UFMG, p. 209-263, 2013. 
NASCIMENTO, Elisa Larkin. A matriz africana no mundo. São Paulo: Selo Negro, 2008.

NOGUERA, Renato. Denegrindo a filosofia: o pensamento como coreografia de conceitos afroperspectivistas. Griot - Revista de Filosofia, Amargosa, Bahia - Brasil, v.4, n.2, p. 1-19, dez/2011.

NOGUERA, Renato. Kiriku: heterônimo da infância como experiência e da experiência da infância. In: Anais [...] do Congresso de Estudos da Infância. - Rio de Janeiro, 2017a, p. 363-370.

NOGUERA, Renato. Pinóquio e Kiriku: infância(s) e educação nas filosofias de Kant e Ramose. Revista AÚ, ano 02, p. 5-18, 2017.

NOGUERA, Renato. Entre a linha e a roda: infância e educação das relações étnicoraciais. Magistro Revista do Programa de Pós-Graduação em Humanidades, Culturas e Artes - UNIGRANRIO, Rio de Janeiro, v.1, n.15, p. 398-419, 2017.

NOGUERA, Renato. Cidade ou Aldeia? Trabalho ou Brincadeira?. Cosmos \& Contextos, Rio de Janeiro, v. 1, n. 15, p. 24-42, 2017.

NOGUERA, Renato; GUTMAN, Catia; FEITOSA, Dayane. Pintando e desenhando Pinóquio e Kiriku na escola. Aprender: caderno de Filosofia e Psicologia da Educação. Vitória da Conquista-BA, Ano XI, n. 19, p. 75-94, jul./dez. 2017.

OLIVEIRA, Eduardo. Cosmovisão Africana no Brasil: elementos para uma filosofia afrodescendente. Curitiba: Gráfica e Editora Popular, 2006.

OYĚWÙMÍ, Oyèrónkẹ́. La invención de las mujeres: una perspectiva africana sobre los discursos occidentales del género. Tradução Alessandro Molengo Gonzalez. Bogotá: La Fronteira, 2017.

ROCHA, Alessandro. Teologia sistemática no horizonte pós-moderno: um novo lugar para linguagem teológica. São Paulo: Editora Vida, 2007.

SARMENTO, Manuel. As culturas da infância nas encruzilhadas da Segunda Modernidade. In: SARMENTO, M.J. \& CERISARA, A.B. (orgs.). Crianças e miúdos: perspectivas sociopedagógicas da infância e educação. Porto: Asa, 2004.

SARMENTO, Manuel Jacinto. Imaginário e culturas da infância. Disponível em: http:www.iec.minho. pt/cedic/textos de trabalho. 2003.

SARMENTO, Manuel Jacinto, PINTO, Manuel. As crianças, contextos e identidade. Braga: Centro de Estudos da Criança/Universidade do Minho, 1997..

STRIEDER, Inácio. Uma perspectiva teológica do trabalho. Perspectiva filosófica, Recife, v. 5, n. 10, p. 27-39, 1997.

SUTOM-SMITH, Brian. The ambiguity of play. Boston: Harvard University Press, 2001 .

TOREN, Christina. Children's perceptions of gender and hierarchy in Figji. In:

JAHODA \& LEWIS (Org.). Acquiring Culture: cross cultural studies in child 
developmente, London and Nova York: Croom Helm, 1988. 